\title{
Young spinal cord injured patients in nursing homes: rehospitalization issues and outcomes
}

\author{
S I Weingarden MD, P Graham RN MS \\ Southfield Rehab Hospital, 22401 Foster Winter Drive, Southfield, Michigan 48075, USA.
}

\begin{abstract}
Most spinal cord injured (SCI) patients are discharged to their homes and families after they complete their initial rehabilitation program. Nursing homes, however, were the discharge destinations for $3.9 \%$ of all SCI patients nationally. When a nursing home is the only discharge option for a young SCI adult, certain economic, medical and psychosocial incongruencies make this placement potentially stressful for both the nursing home staff and the young patient. This study of the rehospitalization of 12 SCI patients under the age of 50 who were discharged to nursing homes explores the issues of cost, care and outcome during their first year following nursing home admission. Nine of the 12 patients were rehospitalized a total of 21 times, mainly for urinary tract infections and decubiti. Charges for 18 of these 21 rehospitalizations amounted to over $\$ 423,110$ for 599 days of care. Four of these 9 patients died before the end of the first year. Although this is a retrospective study of the medical records and follow up data for a small key group of SCI patients, it calls attention to the need for continued investigation into the outcomes of a minimally visible population that lacks advocacy for change.
\end{abstract}

Keywords: spinal cord injury; post hospital care; rehospitalization; nursing home care.

\section{Introduction}

The goal of a spinal cord injury (SCI) rehabilitation program is 'to teach disabled persons to live with their disability in their own environment'. ${ }^{1}$ For the majority of SCI patients, 'their own environment' is their former place of residence or, at least, among family and friends in their own community. Unfortunately, some SCI patients lack the family, friends, functional abilities or finances to return to a private residence; therefore, placement in a nursing home may be the only remaining option. Although only $3.9 \%$ of SCI patients reside in nursing homes nationally, according to 1989 statistics from the National Spinal Cord Injury Statistical Center (NSCISC), the rate for SCI patients in the South-Eastern Michigan Spinal Cord Injury System (SEMSCIS) is $7.1 \%$ The commonest causes of SCI nationally are motor vehicle accidents $(45 \%)$, falls $(21.5 \%)$, violence $(15.5 \%)$ and sports accidents (8.9\%); however, SEMSCIS reports that violence leads with a rate of $42.7 \%$, followed by falls $(26.4 \%)$, vehicle accidents $(20.4 \%)$ and sports accidents $(7.3 \%)$. NSCISC also reports that the occurrence of SCI is highest among males between the ages of 16 and 30 . An injury to the spinal cord is particularly devastating to this age group because of developmental needs demonstrated by pride in physical strength, sexual activity, competitiveness and striving for financial independence. After a SCI the resultant paralysis and loss of sensations, coupled with bladder and bowel involvement, make these needs and the goals of intimacy and independence more difficult to attain for the young disabled adult. Admission into a nursing home means living with a primarily female population with an average age of 86 years. ${ }^{2}$ Elderly nursing home residents are the most frail, cognitively impaired and chronically ill of their age group. Although some similarities may exist in nursing care needs, psychosocial needs differ greatly. Most nursing homes do not have the recre- 
ational programs that will meet the needs of both groups. This age disparity affects diet preferences, privacy needs, visiting hours and other age-appropriate non geriatric routines.

Davidoff $^{3}$ analyzed first-year rehospitalizations after SCI. In his series of 88 patients, 33 patients had 47 readmissions. Of these 47, 16 readmissions were classified as potentially preventable, as they were secondary to preventable complications. There was no breakdown in this study of the ages of these patients or their destination on discharge.

Over the past 5 years, from 1984 to 1989 , SEMSCIS, a model system of SCI care, transferred 12 patients under the age of 50 from its SCI rehabilitation unit to a skilled nursing facility.

The purpose of this paper is to review the post hospital course of these patients during the first year after their discharge from the rehabilitation unit and to determine whether nursing home placement is a cost effective, medically safe environment for a young disabled SCI individual whose life expectancy has been extended to almost that of the average person.

\section{Method}

SEMSCIS staff collected data on all SCI patients who gave informed consent and who had sustained a traumatic injury. Only patients under 50 years of age who were transferred directly from the rehabilitation unit to a nursing facility were included for this study.

Additional follow up information was obtained in accordance with standards of the NSCISC. Patients who were transferred directly from the acute care component of this model SCI system to a nursing facility were not included even if they met the age criterion. No ventilator dependent patients were included in the study, nor patients requiring custodial care.

Demographic data abstracted from the records included age, sex, race, marital status at time of injury, insurer, prior history of substance abuse or a psychiatric diagnosis. In addition, level of injury (paraplegia or quadriplegia) and etiology (motor vehicle accident, gunshot wound, fall or sports injury) were identified. Post hospital data included the timing of the first rehospitalization, number of rehospitalizations, diagnoses, lengths of stay and costs.

\section{Results}

The patients included 10 males and 2 females under 50 years of age. Six males were between the ages of 20 and 30, with an overall mean age of 32 years. All except 2 were black and none were married at the time of discharge. Nine had a history of substance abuse and 5 had a history of psychiatric disorder. Only 2 had no prior history of either diagnosis. None of the patients was transferred to the nursing facility because of an active psychiatric problem. Patients were transferred to a number of different facilities in the community.

The etiologies of the injuries were violence (gunshot wound/assault; 6), motor vehicle accident (3), fall (2), and a diving accident (1). Eight patients were quadriplegics; 4 were paraplegics.

Initial hospital length of stay for the acute care and rehabilitation was similar for both groups. The program, including patients' self care, was similar for all patients. When a patient was transferred to a nursing facility, the staff was invited to attend an instruction program in the patient's care.

The insurance carrier was Medicaid in 10 cases. Two patients were covered by 'nofault' auto insurance and one patient later received additional medical-care benefits and a pension because he was a veteran.

Of the 12 patients, 9 were rehospitalized at least once during the first year after injury. Time until rehospitalization from date to discharge ranged from 7 days to 109 days, with a mean of 40 days. This group had a total of 21 hospitalizations in the first year, of which 10 were for urinary tract infections, 7 for decubitus ulcers, one for a burnt foot, one for bowel obstruction, one for depression, and one for additional rehabilitation.

Hospital charge data were available for 18 of the 21 hospitalizations. Only basic per day costs were provided for 3 hospitaliza- 
tions that accounted for 26 days; therefore, they were not included in total rehospitalization days or costs (see Tables I and II).

The 18 hospitalizations for which all charges were obtained totaled 599 days or a mean of 33.3 days per hospitalization and charges of $\$ 423,110$ or a mean of $\$ 23,506$ in the first year per hospitalization.

Three patients did not require rehospitalization. Two of this group received additional monies that enabled them to start living independently within a year of discharge. One patient remained at the same nursing home and was treated for decubiti and urinary tract infections but was not hospitalized.

\section{Discussion}

Nursing home placement of young SCI patients usually occurs when no other viable option is present. The high rate of rehospitalization seen in this series was mostly secondary to the development of urinary tract infections and of pressure sores and was likely due to numerous problems occurring simultaneously.

Nursing facilities are usually not able to provide the equipment and resource needs of the SCI. Most patients with this injury have bowel and bladder incontinence. In the rehabilitation hospital, bladder incontinence is generally treated with an intermittent catheterization program. Before the patient is discharged to a nursing home, however, the nursing home usually requests the insertion of an indwelling catheter. Intermittent catheterization requires the use of 4-6 sterile catheterization kits daily as well as nursing staff to do the catheterizations if the patient is unable to selfcatheterize. As a result, even if a clean intermittent catheterization program is considered, the labor intensity requirements preclude this as an option in most nursing facilities. In contrast, an indwelling catheter needs to be changed only once every month. An almost inevitable complication from the use of an indwelling catheter is acute urinary tract infections, the most frequent cause of hospital readmissions in these patients. ${ }^{4}$

Pressure sore prevention is the accepted norm in the inpatient setting. The accom- plishment of this is usually labor intensive. Patients require frequent transfers and weight shifts throughout the day and night. This intensive support is difficult to obtain in the nursing facility, especially when the Medicaid reimbursement rate of $\$ 49$ per day in Michigan is considered. When pressure sores do develop, the facilities do not have the necessary additional funding to pay for specialized beds and other equipment to promote healing and prevent worsening. It is not uncommon for new pressure sores to develop because of the positioning needed to relieve pressure on the original wound. The use of sterile dressings and the need for licensed nursing to do the dressing changes also greatly increase the cost to the nursing facility.

Djikers,${ }^{5}$ in a survey of 39 nursing homes in Michigan that had one or more SCI patients, found that recreational programs, if available, were not geared to the interests of young adults. Age-group peers were not present and specialized equipment for quadriplegic patients was generally not available. Without the specialized equipment that SCI patients use in a rehabilitation unit, such as wheelchairs with removable foot and arm rests, wheelchair cushions, electrical wheelchairs, commode chairs and electric beds, patients soon lose the self help skills they attained.

Nursing home placement of young SCI patients occurs at a time when denial of the consequences and permanence of the disability is still intense. If the young patient has used illegal substances to cope with stress prior to the injury, new coping methods must be adopted. The outbursts of anger as well as the symptoms of depression are often misunderstood by nursing home staff who have not been prepared for these reactions to their provision of routine care. Nursing homes that initially admit a young SCI patient with time-consuming nursing care needs, adjustment problems and minimal financial reimbursement may transfer the patient to an acute care hospital as soon as an acute complication, such as urinary tract infection, occurs. The administration may then refuse to readmit the patient to the nursing home if the bed can be filled with a less disabled or more compliant older 
Table I Nursing home patients rehospitalized during first post discharge year

\begin{tabular}{|c|c|c|c|c|c|c|c|c|c|c|c|c|c|c|c|}
\hline Patient & Age & Sex & Race & $\begin{array}{c}\text { Marital } \\
\text { status }\end{array}$ & $\begin{array}{c}\text { Sub } \\
\text { abuse }\end{array}$ & Psych & Etiology & $\begin{array}{l}\text { Injury } \\
\text { level }\end{array}$ & $\begin{array}{l}\text { Initial } \\
\text { rehosp }\end{array}$ & $\begin{array}{c}\text { Number } \\
\text { of } \\
\text { rehosp }\end{array}$ & Causes & $\begin{array}{l}\text { Total } \\
\text { LOS }\end{array}$ & $\begin{array}{l}\text { Total } \\
\text { costs }\end{array}$ & Insurance & $\begin{array}{l}\text { Recent } \\
\text { outcome }\end{array}$ \\
\hline 1 & 20 & $\mathbf{M}$ & B & $\mathrm{S}$ & - & - & GSW & Para & 75 & 2 & $\begin{array}{l}\text { UTI } \\
\text { Burn }\end{array}$ & 14 & $\$ 5,460$ & Medicaid & $\begin{array}{l}\text { Indep } \\
\text { living }\end{array}$ \\
\hline 2 & 34 & $\mathrm{~F}$ & B & Div & + & + & Fall & Para & 36 & 2 & $\begin{array}{l}\text { UTI } \\
\text { Decub }\end{array}$ & 73 & $\$ 37,428$ & Medicaid & $\begin{array}{l}\text { Died } \\
7.5 \text { months }\end{array}$ \\
\hline 3 & 25 & $\mathbf{M}$ & B & $\mathrm{S}$ & + & - & GSW & Quad & 34 & 2 & $\begin{array}{l}\text { UTI } \\
\text { Decub }\end{array}$ & 68 & $\$ 37,039$ & Medicaid & $\begin{array}{l}\text { Nursing } \\
\text { home }\end{array}$ \\
\hline 4 & 36 & $\mathbf{M}$ & W & Div & + & - & MVA & Quad & 38 & 3 & $\begin{array}{l}\text { UTI } \\
\text { Bow Obs }\end{array}$ & 61 & $\$ 65,029$ & Auto & $\begin{array}{l}\text { Died } \\
3 \text { years }\end{array}$ \\
\hline 5 & 27 & $\mathbf{M}$ & B & $\mathrm{S}$ & - & + & Dive & Quad & 9 & 1 & $\begin{array}{l}\text { UTI } \\
\text { Decub }\end{array}$ & 30 & $\$ 27,400$ & Medicaid & $\begin{array}{l}\text { Died } \\
1 \text { year }\end{array}$ \\
\hline 6 & 25 & M & B & $\mathrm{S}$ & - & - & GSW & Quad & 7 & 1 & $\begin{array}{l}\text { UTI } \\
\text { Decub }\end{array}$ & 24 & $\$ 15,982$ & Medicaid & $\begin{array}{l}\text { Indep } \\
\text { living }\end{array}$ \\
\hline 7 & 46 & $\mathbf{M}$ & B & $\mathrm{S}$ & + & + & Fall & Para & 35 & 5 & $\begin{array}{l}\text { UTI } \\
\text { Decub }\end{array}$ & 183 & $\$ 163,437$ & Medicaid & $\begin{array}{l}\text { Died } \\
8 \text { months }\end{array}$ \\
\hline 8 & 28 & $\mathbf{M}$ & B & $\mathrm{S}$ & + & + & GSW & Quad & 94 & 4 & $\begin{array}{l}\text { UT1 } \\
\text { Depres }\end{array}$ & 160 & $\$ 76,795$ & Medicaid & $\begin{array}{l}\text { Indep } \\
\text { living }\end{array}$ \\
\hline 9 & 42 & $\mathrm{~F}$ & B & $\mathrm{S}$ & + & - & Assault & Quad & 109 & 1 & Decub & 12 & $\$ 13,780$ & Medicaid & $\begin{array}{l}\text { Died } \\
4 \text { months }\end{array}$ \\
\hline
\end{tabular}

$\mathrm{M}=$ male; $\mathrm{F}=$ female; $\mathrm{B}=$ black; $\mathrm{W}=$ white $\mathrm{S}=$ single; Div = divorced; Psych = psychiatric disorder; GSW = gunshot wound; $\mathrm{MVA}=$ motor vehicle accident Para = paraplegic; Quad = quadriplegic; UTI = urinary tract infection; Decub = decubitus ulcers; Bow obs = bowel obstruction; Depres = depression; LOS $=$ length of stay.

Table II Nursing home patients not rehospitalized during first discharge

\begin{tabular}{|c|c|c|c|c|c|c|c|c|c|c|c|}
\hline Patient & Age & Sex & Race & $\begin{array}{l}\text { Marital } \\
\text { status }\end{array}$ & $\begin{array}{l}\text { Sub } \\
\text { abuse }\end{array}$ & Psych & Etiology & $\begin{array}{l}\text { Injury } \\
\text { level }\end{array}$ & $\begin{array}{l}\text { LOS } \\
\text { Nursing Home }\end{array}$ & Insurance & $\begin{array}{l}\text { Recent } \\
\text { outcome }\end{array}$ \\
\hline 1 & 44 & $\mathbf{M}$ & B & $\mathrm{S}$ & + & - & $\begin{array}{l}\text { Ped } \\
\text { MVA }\end{array}$ & Quad & 4 years & $\begin{array}{l}\text { Medicaid } \\
\text { \& Auto }\end{array}$ & Nursing home \\
\hline 2 & 36 & $\mathbf{M}$ & B & Div & + & + & GSW & Para & 6 months & Medicaid & Indep living \\
\hline 3 & 21 & $\mathbf{M}$ & W & $\mathrm{S}$ & + & - & MVA & Quad & 49 days & Auto & Indep living \\
\hline
\end{tabular}

Ped $=$ pedestrian. For rest of abbreviations, see Table $\mathrm{I}$. 
patient. In some instances, the SCI patient may refuse to return to that nursing home and may request placement in another facility. The hope that the next nursing home will be much better is seldom realized and the cycle of discharge and readmission continues.

Young adults who were struggling to accept the reality of their disability, as well as the unwillingness or inability of family and friends to offer help, must now face the fact that their preferences are limited by the amount of care they need and the amount of money their insurance provides to the nursing home. Geographic proximity to family members, number of other young patients in the facility, self directed care and provision of activities that promote independence and personal worth have been recognized as essential factors in the selection of a nursing home by young men in an SCI unit of a veterans' hospital. ${ }^{6}$ These preferences, however, receive little consideration when Medicaid is the payment source.

A final consideration is the attitudes of the treating team and the patient prior to discharge from the rehabilitation hospital. During the time the patient is in the hospital, success for the team is defined as getting the patient back home. The inability to do so is usually perceived as a failure by the treating team. This attitude is not lost on the patient, who then perceives himself as a failure for going to the nursing home.

The combination of these factors-inadequate funding for the facility to provide proper equipment and staffing, inappropriate social milieu, anger and poor self perception - is likely to lead to depression. This may explain why these complications occur even though the patients have been instructed and trained in their prevention.

Alternatives to nursing home placement appear to be much more costly, until the costs of rehospitilization are included with nursing home costs. If this is done, it is likely that the alternatives are indeed less expensive.

SCI patients who live independently are eligible for supplemental security income. They receive $\$ 416$ monthly in addition to other necessary services such as a chore person, medical assistance and food stamps.
Section 8 federally subsidized housing in wheelchair-accessible apartments could provide the opportunity for young SCI patients to live independently and hire attendant care. However, the number of apartments that are wheelchair accessible is far less than the demand for them, and elderly disabled people are given first preference particularly in a senior citizen apartment complex. Expansion of this program should be a prime consideration.

Group homes have proven effective both in cost containment and in promoting quality of life for mentally retarded young adults. Shared housing and attendant care costs combined with companionship and a sense of empowerment have made this option successful.

Centers for independent living teach disabled persons how to live independently through classes in budgeting, hiring help, accessing agencies, becoming assertive and finding housing. Unless daily transportation to the center is provided, the nursing home patient, however, cannot attend.

Towards those patients for whom a nursing facility remains the only option, a different approach must be taken during the rehabilitation program. Once it is recognized that a nursing home placement appears likely, the program should be structured for the patient to learn the proper techniques to survive and thrive in the facility. Instruction in assertiveness and directing care in that environment is critical. Once accomplished, at transfer all involved will feel that the rehabilitation program was a success.

\section{Summary}

Young SCI patients who enter nursing homes after discharge from a rehabilitation hospital face obstacles in obtaining the quality of care that will prevent the complications of urinary tract infections, decubitus ulcers and sepsis. Although a prior history of substance abuse and psychiatric disorders impacts on adjustment to living in a nursing home, the lack of recreational programs for young residents and limited resources for substance abuse and mental health treatment further compound the problems. 
The outcomes of the 12 patients included in this study should raise issues about overall cost effectiveness of nursing home placement without the provision of equipment and services that are considered to be essential for the good management of this disability. Model SCI systems that are funded to follow up patients over a long period of time can include statistics on young institutionalized disabled people so that their visibility is not hidden by benign neglect. Since 4 of the 9 patients died within the first year following discharge, there is a clear indication that young nursing home patients may have a very high mortality rate regardless of the severity of their disability.

More alternatives to nursing home placement are needed, as are more funds to provide those services that promote independent living.

\section{References}

1 Trieschmann R (1988) Spinal Cord Injuries: Psychological, Social and Vocational Rehabilitation. Demos, New York: 26.

2 Libow LS, Starer P (1989) Care of the nursing home patient. $N$ Engl J Med 321: 93-96.

3 Davidoff G, Schultz JS, Lieb T, Andrews K, Wardner J, Hayes C et al (1990) Rehospitalization after rehabilitation for acute spinal cord injury: incidence and risk factors. Arch Phys Med Rehab 71: 121-124.

4 Stover SL, Fine PR, editors. Spinal Cord Injury: The Facts and Figures. University of Alabama Press, Birmingham.

5 Djikers M, Graham P (1985) The Potential for Nursing Home Placement of SCI Patients: A Survey of Michigan Nursing Homes. American Spinal Injury Association, Atlanta.

6 Ulmer D (1990) Special needs of the young spinal cord injured patient in a nursing home. SCI Nursing 7: $27-30$. 